\title{
Frequency of flower visitors and achene production increase with rising population size in the self-incompatible herb Centaurea scabiosa (Asteraceae)
}

\author{
Stefan Abrahamczyk (D) Mirjam Thielen - Maximilian Weigend
}

Received: 15 December 2020/ Accepted: 8 March 2021 / Published online: 22 March 2021

(C) The Author(s) 2021

\begin{abstract}
Self-incompatible, non-clonal plant species are especially dependent on the activity of flower visitors for seed production. Therefore, populations of these plants are vulnerable to a reduced flower visitation rates, but also to increased isolation by extinction of local populations. To study how local populations of Centaurea scabiosa, a self-incompatible, bee-pollinated herb species changed over time in the region of Bonn, we collected historical population records in the area and investigated their current status. We found that more than half of the subpopulations mentioned in the literature between 1950 and 2012 (38 of 65) have since disappeared. Small populations were most vulnerable, whereas medium to large populations increased in size. In a second step, we studied visitation frequencies and achene production and weight across 14 extant populations. We found that both flower visitation frequency and achene production were positively related to population size. Achene weight was neither related to the frequency of flower visitors nor to achene production. These results
\end{abstract}

Communicated by Philip Ladd.

Supplementary Information The online version contains supplementary material available at https://doi.org/10.1007/ s11258-021-01129-1.

S. Abrahamczyk $(\bowtie) \cdot$ M. Thielen $\cdot$ M. Weigend Nees-Institute for Biodiversity of Plants, University of Bonn, Meckenheimer Allee 170, 53115 Bonn, Germany e-mail: stefan.abrahamczyk@uni-bonn.de clearly indicate that reduced pollen transfer and lower pollination rates may contribute to local extinction in small populations of Centaurea scabiosa. Overall our results call for an intensified monitoring of the populations of self-incompatible plant species.

Keywords Bee pollination - Geographical isolation Inbreeding · Land use change - Local extinction .

Pollinator loss $\cdot$ Population size

\section{Introduction}

In the past decades, the diversity and abundance of flower-visiting insects has dramatically decreased in many Central European habitats due to habitat loss, fragmentation, a reduced food availability and the massive application of pesticides in agriculture (e.g. Biesmeijer et al. 2006; Brittain et al. 2010; de Palma et al. 2016; Abrahamczyk et al. 2020). This decline is expected to have a negative impact on pollination services and consequently on the conservation status of obligately entomophilous plant species (Biesmeijer et al. 2006). Self-incompatible species, dependent on active pollen transfer and high outcrossing rates for successful seed production (Jennersten 1988; Ågren 1996) are expected to be particularly vulnerable. These plant species commonly have large, attractive flowers with high pollination reward (nectar and/or 
pollen) and are, therefore, important food resources for many species of flower visitors.

Seed set, seed weight and seedling survival of selfincompatible plants are strongly reduced or nullified if pollinated by self-pollen or by pollen from closely related individuals (Broyles and Wyatt 1993; Culley et al. 1999; Schlindwein et al. 2005). Chronically reduced seed production necessarily leads to population decline and may even result in local extinction because small populations are increasingly unattractive to pollinators, which often prefer species with large populations. This, in turn, further reduces visitation rates and seed set (Ågren 1996; Groom 1998). Additionally, small populations have a higher extinction risk due to inbreeding and genetic drift (Campbell and Husband 2007). If more and more populations of a species go extinct within a region, the remaining populations become increasingly isolated. This fragmentation reduces gene flow and reduces seed production (Ghazoul 2005). Gene flow between isolated populations can be maintained either by pollinators or by seed dispersal: However, gene flow by pollinators is limited by the distance between populations since especially smaller insects often forage within one kilometre around their brood sites (Walther-Hellwig and Frankl 2000; Zurbuchen et al. 2010; Hofmann et al. 2020). Seed dispersal, in turn, can only maintain gene flow if appropriate adaptations exist and dispersal vectors are functional (Ghazoul 2005).

Centaurea scabiosa is a useful model to study the effects of population size on reproductive success: It is a conspicuous, self-incompatible, non-clonal, perennial herb (Marsden-Jones and Turrill 1954; Jäger 2016), widely distributed across Western Europe to Central Siberia. However, it tends to have a scattered distribution with populations restricted to suitable habitats such as dry meadows or ecologically comparable man-made secondary habitats such as road cuttings (Hofmann et al. 2013). In Germany it is moderately common, but shows a modest population decline (www.rote-liste-zentrum.de). Most importantly, quite detailed historical data on the distribution of Centaurea scabiosa since the 1950s are available for the region of Bonn (Gorissen 2013), enabling us to study the changes of the populations across the past decades.

The flower heads (capitulescences) of Centaurea scabiosa are composed of several tubular, reddish purple flowers that open between June and September (Jäger 2016). The flowers are mostly visited by a range of long-tongued bee species, especially of the genus Bombus, but also by short-tongued bees, syrphid flies and butterflies (Lack 1982a; Ehlers 1999). Flower visitors are rewarded by nectar (Lack 1982b). The achenes of Centaurea scabiosa are dispersed by ants as well as epi- and endozoochorously by large mammals (Jäger 2016). A Danish study (Ehlers 1999) did not find a significant relationship between population size and the number of achenes per capitulescence in Centaurea scabiosa, but did report a high variation of seed set within and between sites. Additionally, Ehlers (1999) did not find a significant relationship between visitation rate and population size studying five medium to large populations (27, 250, 300, 350, 650 individuals).

To overcome the weaknesses of small sampling size and moderate variability in population size in the study by Ehlers (1999) we analysed population dynamics, flower visitation frequency and achene production of Centaurea scabiosa. We expanded our sampling to a total of 14 populations, ranging from 1 to 22,340 individuals in the Bonn region. We compared decadal changes in population sizes and correlated population sizes to the frequency and diversity of flower visitors as well as to achene production and weight. Specifically, we tested the following hypotheses:

1. The number and size of populations of Centaurea scabiosa have declined in the region of Bonn since the 1950s.

2. Flower visitation rates and the diversity of flower visitors are positively correlated to population size in Centaurea scabiosa.

3. Achene production and weight are positively related to population size in Centaurea scabiosa.

\section{Material and methods}

\section{Change of populations over time}

We tabulated historical reports on populations of Centaurea scabiosa in the city of Bonn and the adjacent Rhein-Sieg Kreis, dating from the 1950s to 2012 from Gorissen (2013) and also noted the number of individuals per population (Table S1). We 
standardised reported population sizes by defining five individuals for descriptions like "few individuals" or "remnants", ten individuals for descriptions like "small population" or "several individuals". Descriptions such as "many" or "very many" individuals could not be translated. To identify additional current populations of Centaurea scabiosa in the area we used point localities from the website of the "Landesamt für Natur, Umwelt und Verbraucherschutz NordrheinWestfalen" (LANUV; www.florenkartierung-nrw. de), our own observations as well as interviews with local botanists (e.g. pers. com. Jutta Bohne, Wolfram Lobin, Bodo Moeseler, Heiko Schmied). We georeferenced all known population and visited them from March to May 2020 to verify current status and to assess population sizes.

Stands of Centaurea scabiosa were treated as representing separate population when they were separated by $>1000 \mathrm{~m}$. Two or more groups of plants 500-1000 m apart from each other were treated as subpopulations of one population. The distance between (sub-)populations was obtained from Google Earth ${ }^{\circledR}$. We chose a distance of $>1000 \mathrm{~m}$ because bees, the main pollen vectors for Centaurea scabiosa (Ehlers 1999), mostly forage within a radius of roughly $1000 \mathrm{~m}$ around their nests (Walther-Hellwig and Frankl 2000; Zurbuchen et al. 2010; Hofmann et al. 2020).

We estimated population size in two ways: We performed a total count of individuals for small populations covering less than $1000 \mathrm{~m}^{2}$. In populations covering $>1000 \mathrm{~m}^{2}$ we counted the number of individuals in a number of $2 \mathrm{~m} \times 2 \mathrm{~m}$ squares ranging from four squares for areas with $1000 \mathrm{~m}^{2}$ to 24 squares for areas with $22,700 \mathrm{~m}^{2}$. Within each area we arranged the position of the squares in a way to optimally represent the variability in plant density. We analysed the area covered by a population by connecting the outermost plant individuals and calculating the area of the resulting polygon in Google Earth ${ }^{\circledR}$. We calculated the number of plants per population by multiplying the average number of individuals per unit area $\left(\mathrm{m}^{2}\right)$ obtained from the direct counts with the total population area.

\section{Observations of flower visitors}

Based on our population observations we selected 30 populations of Centaurea scabiosa (ranging from very small to very large) for the subsequent study. In June 2020 we revisited these populations and counted the Centaurea scabiosa individuals with inflorescences following the methodology described above. In some (sub-)populations these numbers were different from the number of sterile individuals because some meadows had been mown. Out of these 30 populations we finally chose 14 populations ranging from one to 22,340 individuals (Table 1) for observations and analyses of flower visitors and achene production. We only selected populations for which we could be sure that they had not been mown within the previous weeks. The populations analysed were situated 2.3-32.6 km from each other. We additionally verified that within an area of $1 \mathrm{~km}$ around each population analysed no other flowering individuals of Centaurea scabiosa existed.

In July and August 2020 we recorded flower visitors of Centaurea scabiosa over 4 days, each for $2.5 \mathrm{~h}$ in all populations $(=10 \mathrm{~h}$ total observation time per population). Observation time was subdivided into 30 min time slots. We observed flower visitors within a $2 \mathrm{~m} \times 2 \mathrm{~m}$ square in the centre of each population and marked the capitulescences at which we observed the flower visitors with red cotton yarn. We recorded the number of insect individuals per species alighting on the capitulescences and touching anthers and/or stigmas. We were unable to count the number of individual florets visited within the capitulescence due to the small size of the single florets and the high number of flower visitors.

To identify the individual species of flower visitors of Centaurea scabiosa we caught representatives of all morpho species at each site and transferred them into snap cup vials. Then, we put these vials into a cooler bag and cooled them down for a few minutes. By this procedure the insects became inactive and we could place them onto a grey background to take photographs from different angles. All insects were subsequently released unharmed. The insect visitors were identified based on the images and with the help of pertinent literature (Harde and Severa 1988; von Hagen and Aichhorn 2003; Amiet and Krebs 2014; Ball and Morris 2015; Westrich 2018).

Achene production and weight

To analyse the impact of population size and frequency of flower visitors on the achene production of 


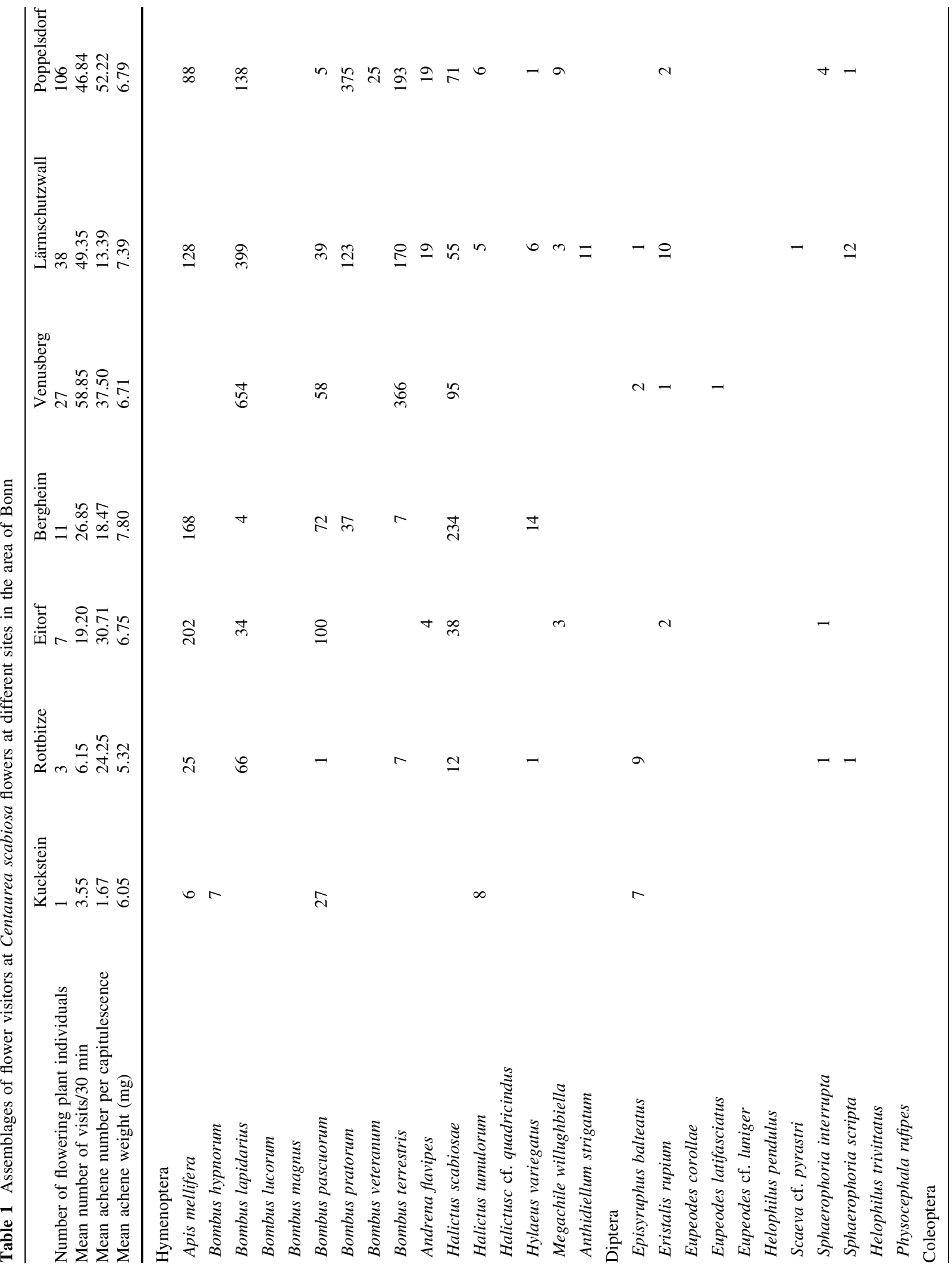




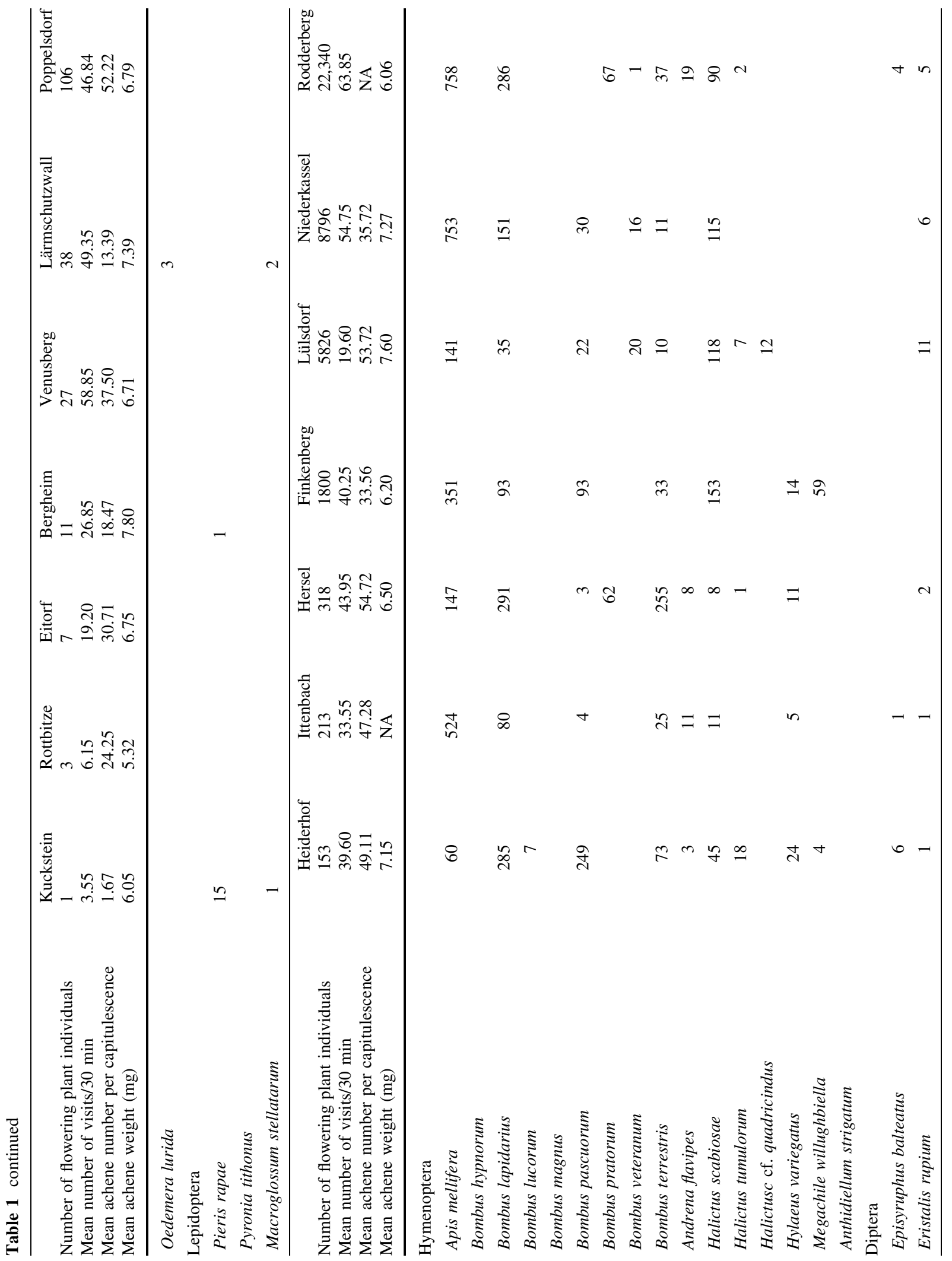




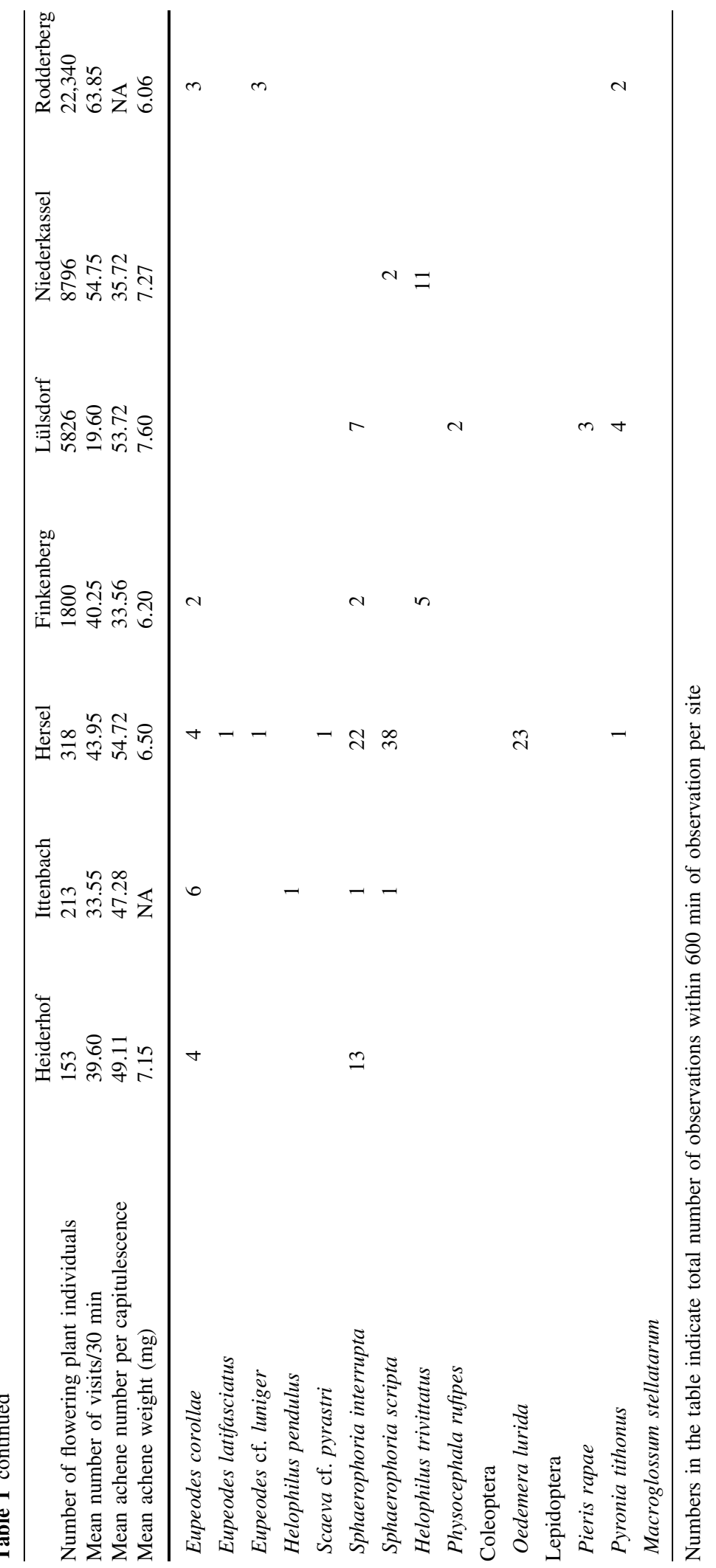


Centaurea scabiosa we collected three capitulescences of six individuals each in the centre of each population shortly before the capitulescences began opening and releasing the achenes. We chose the capitulescences previously used for observations of flower visitors. The capitulescences were air-dried for 7 days, opened in the lab and the achenes were removed for counting. Achenes were considered as fully developed when at least the dorsal or the ventral side was convex and the fruit wall was lustrous dark brown. After counting we weighted all achenes using an analytic balance (Mettler Toledo, XS205 Dual Range, $d=0.01 \mathrm{mg}$ ).

\section{Statistics}

To analyse changes in subpopulation abundance of Centaurea scabiosa in the region of Bonn we subdivided the 28 historical subpopulations (coming from 21 populations) for which abundance data were available into two groups: subpopulation $\leq 10$ individuals and subpopulations with $>10$ individuals. Then, we tested with paired Wilcoxon tests per group whether subpopulation size has increased or decreased over time.

To test for a relationship between the visitation frequency and visitor diversity against the logarithmic number of flowering Centaurea scabiosa individuals per population we conducted linear regression analyses.

We used linear models analysing mean achene production per capitulescence against logarithmic population size and visitation frequency to identify whether these two factors correlated to achene production in Centaurea scabiosa. In these analyses we had to exclude the data from our largest population (Rodderberg) since at this locality a large population of seed-predating birds (European Goldfinch, Carduelis carduelis) was continuously present, feeding regularly at Centaurea scabiosa seeds and depleting our marked capitulescences. In a second step we applied linear models analysing mean achene weight per population against logarithmic population size and frequency of flower visitors.

All statistical tests were conducted in $\mathrm{R}$ version 3.4.3 (R Development Core Team 2017).

\section{Results}

Change of populations over time

Of the 41 populations (including 65 subpopulations) of C. scabiosa reported in Gorissen (2013), 24 populations (including 27 subpopulations) are still extant (Table S1), $41.5 \%$ of the populations and $58.5 \%$ of the subpopulations went extinct. We report six additional populations and five subpopulations not reported in Gorissen (2013).

We found historical abundance data for 28 subpopulations of $C$. scabiosa coming from 21 populations. Nine of the 13 subpopulation with $\leq 10$ individuals went extinct, while four increased. A paired Wilcoxon test did not, however, find a significant trend ( $V=48$, $p=0.889$ ). Remarkably, only one of the 15 subpopulations with $>10$ individuals disappeared, while two decreased and 12 increased in size. A paired Wilcoxon test found a significant increase in subpopulation sizes $(V=14, p=0.007$; Fig. 1).

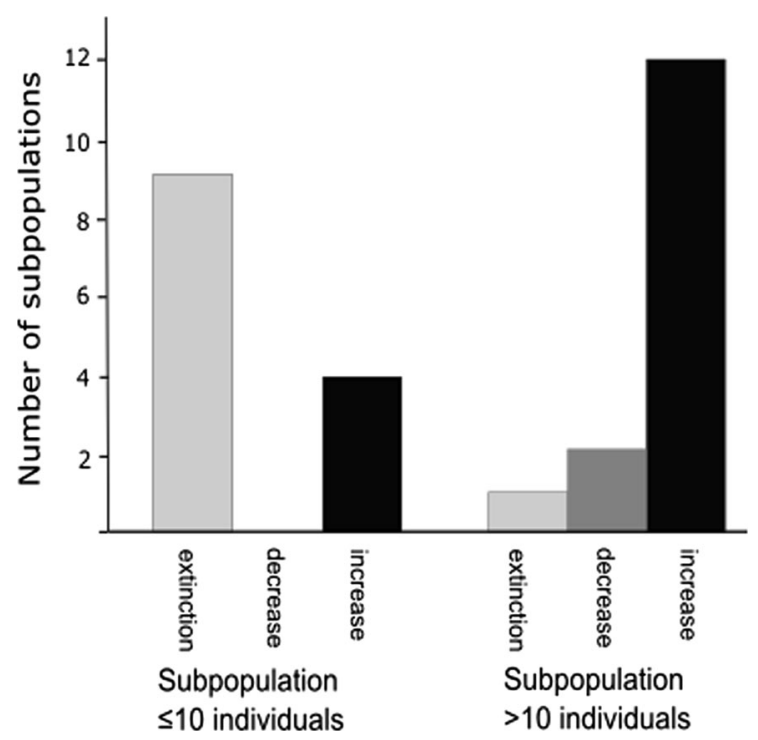

Fig. 1 Development of large and small subpopulation of Centaurea scabiosa in and around Bonn. Note that subpopulations $\leq 10$ individuals did not show significant changes (paired Wilcoxon test: $V=48, p=0.889$ ), while subpopulations $>10$ individuals significantly increased (paired Wilcoxon test: $V=14, p=0.007$ ) 
Observations of flower visitors

The flowers of $C$. scabiosa were mostly visited by long-tongued bees ( 8 species; Fig. 2, Table 1), especially by Apis mellifera and Bombus spp. However, short-tongued bees ( 8 species) and syrphid flies (10 species) were also common flower visitors. Other groups of flies (1 species), beetles (1 species) and butterflies (3 species) only rarely visited the flowers. Five species, e.g. Apis mellifera and Bombus lapidarius were observed in nearly all $(\geq 12)$ populations, five species, e.g. Hylaeus variegatus and Eristalis rupium were found as common flower visitors (occurrence in 8-10 populations), eleven species such as Bombus pratorum and B. veteranum were site specific, but locally common visitors (occurrence in $\leq 50 \%$ of the population with $\geq 10$ observations in at least one

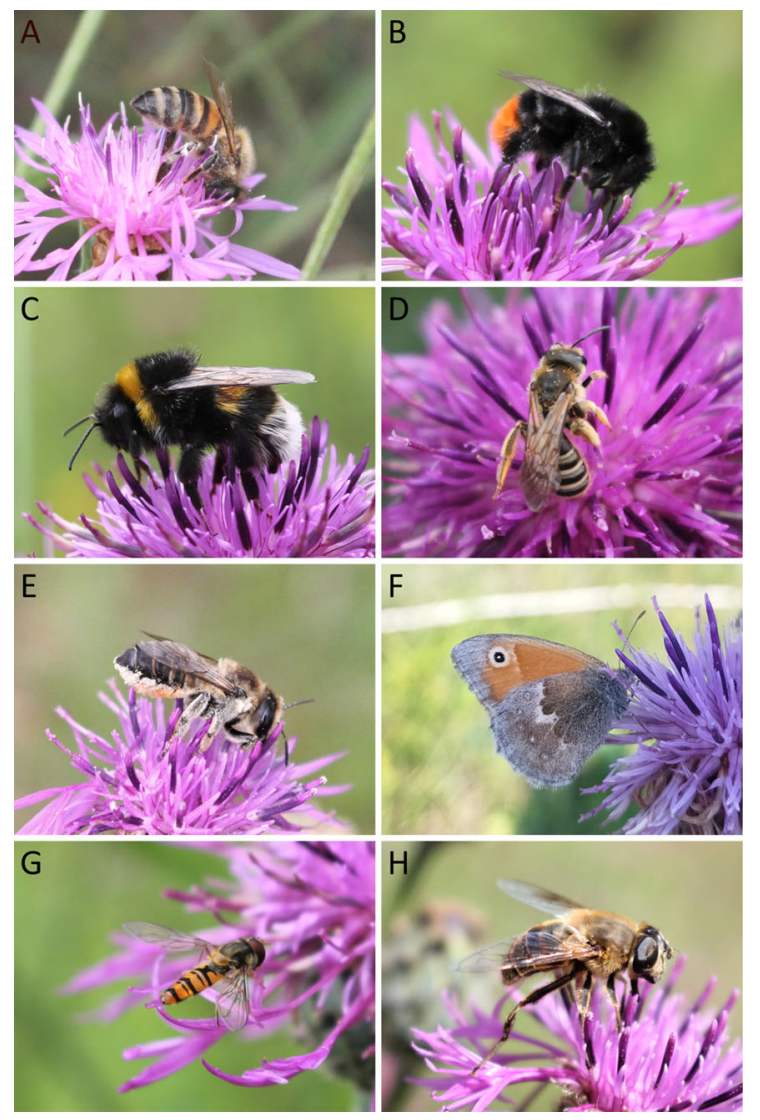

Fig. 2 Flower visitors at capitulescences of Centaurea scabiosa; a Apis mellifera; b Bombus lapidaries; c Bombus terrestris; d Halictus scabiosidae; e Megachile willughbiella; f Pyronia tithonus; $\mathbf{g}$ Episyruphus balteatus; and $\mathbf{h}$ Eristalis rupium site) and 11 species were only rarely observed (occurrence in $\leq 50 \%$ of the population with $\leq 10$ observations per site). Locally common visitor species occurred in all populations $\geq 38$ individuals of $C$. scabiosa.

The flower visitation frequency is significantly and positively related to log population size of C. scabiosa $\left(R^{2}=0.38, p=0.019\right.$; Fig. 3$)$, but there is no significant correlation between log population size and visitor diversity $\left(R^{2}=0.153, p=0.168\right.$; Fig. 3$)$, although very small populations $(<30$ individuals $)$ appear to have an impoverished flower visitor community compared to large populations.

Achene number and weight

Achene number per capitulescence of C. scabiosa increased significantly with increasing $\log$ population size of $C$. scabiosa $\left(R^{2}=0.425, p=0.015\right.$; Fig. 3$)$, but it is not significantly related to flower visitation frequency $\left(R^{2}=0.165, p=0.169\right)$. Achene weight is neither significantly related to flower visitation frequency of $\left(R^{2}=0.051, p=0.459\right)$ nor $\log$ population size $\left(R^{2}=0.089, p=0.322\right)$.

\section{Discussion}

We investigated changes in population size of Centaurea scabiosa in the region of Bonn and the possible correlations between population size and reproductive success. The number of populations of $C$. scabiosa in the study region changed significantly: $40-60 \%$ of all populations and subpopulations mentioned in the literature between 1950 and 2012 (summarised in Gorissen 2013) have disappeared, while only few new populations appeared. Small populations were most negatively affected, whereas medium-sized and large populations increased in population size. These increases in population size as well as the establishment of new populations are mostly induced by infrastructure development, i.e. the construction of roads or dikes, on or along which $C$. scabiosa among other species of dry meadows have been actively established and managed (pers. comm., Klaus Weddeling). The loss of populations is commonly induced by changes in land use of the formally dry meadows and our data clearly show that small populations are 

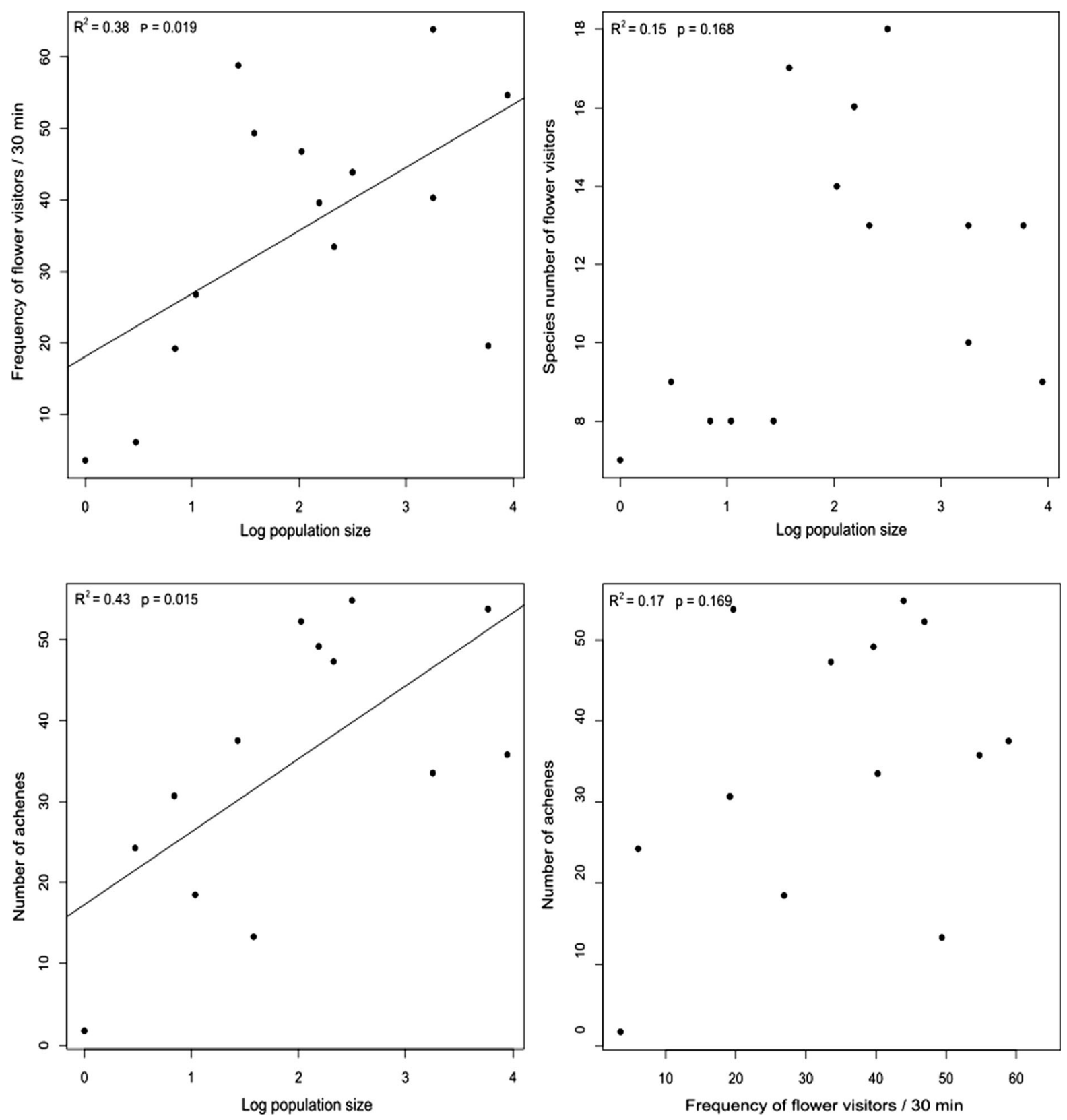

Fig. 3 Regression analyses indicating that frequency of flower visitors and the number of achenes per capitulescence is positively related to $\log$ population size. Species number of

less resilient and more likely to disappear, which has serious implications for conservation.

One possible mechanism for population breakdown is a loss of fertility, e.g. due to reduced pollination or fruit set occasioned by loss of pollinators and/or inbreeding depression due to small population size and

flower visitors and log population size, respectively, the number of achenes and frequency of flower visitors are not significantly related to each other

isolation. Our data show that while the total number of individuals of $C$. scabiosa has increased in the region, the remaining populations have become more isolated. This fragmentation would be expected to negatively affect reproductive success in a self-incompatible species such as C. scabiosa (Ghazoul 2005). 
Geographical isolation and small population size often lead to a reduced visitation rate by flower visitors (e.g. Jennersten 1988; Dauber et al. 2010). In our study, there is a strong positive correlation between flower visitation frequency, respectively, fruit set on the one hand and population size on the other (Fig. 3). Our smallest population had a visitation rate 18 times lower than the largest population. While there is no significant statistical correlation between visitor diversity and population size, the five smallest populations had the lowest number of visitor species compared to all but one other population. The small populations have only a subset of the overall range of flower visitors, lacking even some of the common visitors reported from larger populations. However, the diversity and composition of flower visitor species was highly variable in the medium-sized and large populations of $C$. scabiosa. This may be explained by variation in habitat size and resource availability as well as composition of flower visitor diversity. All of these factors lead to variation in resource partitioning by flower visitors (Geslin et al. 2016). Overall, our results clearly demonstrate that small populations of C. scabiosa are less attractive to flower visitors, which can be explained by the flower fidelity of bees and other groups of flower visitors (Amaya-Márquez 2009). Many flower visitors favour common, abundant resources over the smaller resources offered by the few flowers of an individual species and may end up ignoring rare species (Goulson et al. 1997; Goulson 1999). A common mechanism found in naturally rare species, such as many non-rewarding orchid species that has evolved to overcome this is mimicing the flowers of common species within their habitats (Johnson 2000).

Interestingly, seed set is not significantly correlated to visitor frequency (Fig. 3), indicating that pollination quality is the driving force behind fruit set-the mere presence of insects moving pollen between a small number of plants is evidently not enough to ensure high seed set. Pollination quality may be associated with the heterozygosity of the pollen load delivered and this would provide a direct correlation to population size - and presumably genetic diversityand seed set. However, since we only measured visitation rates, not pollen transfer rates, we cannot rule out that impoverished pollinator communities in small populations differed sufficiently in pollen transfer rates to compromise successful pollination despite similar visitation rates, or that smaller plant number led to an increase in geitonogamous pollination and stigma clogging. Overall, the net result is not surprising: a positive correlation between seed set and population size has been repeatedly reported (e.g. Jennersten 1988; Ågren 1996; Groom 1998; Dauber et al. 2010).

Future studies might address the exact mechanism behind the correlation between population size and reduced fruit set. Independently of the exact driver, the present study underscores the inverse relationship between population size and likelihood of local extinction in C. scabiosa as a non-clonal, self-incompatible herb.

Acknowledgements We thank Julian Kokott for supporting us with insect collection, Jutta Bohne, Wolfram Lobin, Bodo Moeseler, Heiko Schmied and Klaus Weddeling (Biologische Station im Rhein-Sieg Kreis) for comments on additional populations of Centaurea scabiosa, the Amt für Umwelt, Verbraucherschutz und Lokale Agenda of Bonn, the Amt für Umwelt- und Naturschutz of the Rhein-Sieg Kreis), Büro für Natur- und Umweltschutz of St. Augustin and the environmental officer of Niederkassel for permissions to work in the different nature reserves and Jürgen Esser for support in bee species identification.

Open Access This article is licensed under a Creative Commons Attribution 4.0 International License, which permits use, sharing, adaptation, distribution and reproduction in any medium or format, as long as you give appropriate credit to the original author(s) and the source, provide a link to the Creative Commons licence, and indicate if changes were made. The images or other third party material in this article are included in the article's Creative Commons licence, unless indicated otherwise in a credit line to the material. If material is not included in the article's Creative Commons licence and your intended use is not permitted by statutory regulation or exceeds the permitted use, you will need to obtain permission directly from the copyright holder. To view a copy of this licence, visit http://creativecommons.org/licenses/by/4.0/.

Author contributions All authors contributed to the study conception and design. Material preparation, data collection and analysis were performed by MT and SA. The first draft of the manuscript was written by SA and all authors commented on previous versions of the manuscript. All authors read and approved the final manuscript.

Funding Open Access funding enabled and organized by Projekt DEAL. 


\section{References}

Abrahamczyk S, Wohlgemuth T, Nobis M, Nyffeler R, Kessler M (2020) Shifts in food plant abundance for flower-visiting insects between 1900 and 2017 in the canton of Zurich, Switzerland. Ecol Appl 30:e02138

Ågren J (1996) Population size, pollinator limitation, and seed set in the self-incompatible herb Lythrum salicaria. Ecology $77: 1779-1790$

Amaya-Márquez M (2009) Floral constancy in bees: a revision of theories and a comparison with other pollinators. Rev Colomb Entomol 35:206-216

Amiet F, Krebs A (2014) Bienen Mitteleuropas, Gattungen, Lebensweise, Beobachtung. Haupt Verlag, Bern

Ball S, Morris R (2015) Britain's hoverflies. Princeton University Press, Princeton

Biesmeijer JC, Roberts SP, Reemer M, Ohlemüller R, Edwards M, Peeters T, Settele J (2006) Parallel declines in pollinators and insect-pollinated plants in Britain and the Netherlands. Science 313:351-354

Brittain CA, Vighi M, Bommarco R, Settele J, Potts SG (2010) Impacts of a pesticide on pollinator species richness at different spatial scales. Basic Appl Ecol 11:106-115

Broyles SB, Wyatt R (1993) The consequences of self-pollination in Asclepias exaltata, a self-incompatible milkweed. Am J Bot 80:41-44

Campbell LG, Husband BC (2007) Small populations are matepoor but pollinator-rich in a rare, self-incompatible plant, Hymenoxys herbacea (Asteraceae). New Phytol 174:915-925

Culley TM, Weller SG, Sakai AK, Rankin AE (1999) Inbreeding depression and selfing rates in a self-compatible, hermaphroditic species, Schiedea membranacea (Caryophyllaceae). Am J Bot 86:980-987

Dauber J, Biesmeijer JC, Gabriel D et al (2010) Effects of patch size and density on flower visitation and seed set of wild plants: a pan-European approach. J Ecol 98:188-196

de Palma A, Abrahamczyk S, Aizen MA et al (2016) Predicting bee community responses to land-use changes: effects of geographic and taxonomic biases. Sci Rep 6:31153

Ehlers BK (1999) Variation in fruit set within and among natural populations of the self-incompatible herb Centaurea scabiosa (Asteraceae). Nord J Bot 19:653-663

Geslin B, Le Féon V, Folschweiller M, Flacher F, Carmignac D, Motard E et al (2016) The proportion of impervious surfaces at the landscape scale structures wild bee assemblages in a densely populated region. Ecol Evol 6:6599-6615

Ghazoul J (2005) Pollen and seed dispersal among dispersed plants. Biol Rev 80:413-443

Gorissen I (2013) Flora der Region Bonn (Stadt Bonn und Rhein-Sieg-Kreis). Verlag Ingmar Gorissen, Bonn, pp 527-528

Goulson D, Ollerton J, Sluman C (1997) Foraging strategies in the small skipper butterfly, Thymelicus flavus: when to switch? Anim Behav 53:1009-1016

Goulson D (1999) Foraging strategies of insects for gathering nectar and pollen, and implications for plant ecology and evolution. Perspect Plant Ecol Evol Syst 2:185-209
Groom MJ (1998) Allee effects limit population viability of an annual plant. Am Nat 151:487-496

Harde KW, Severa F (1988) Der Kosmos-Käferführer. Franckh'sche Verlaghandlung, Stuttgart.

Hofmann M, Bütof A, Welk E, Bruelheide H (2013) Relationship between fundamental and realized niches in terms of frost and drought resistance. Preslia 85:1-17

Hofmann MM, Fleischmann A, Renner SS (2020) Foraging distances in six species of solitary bees with body lengths of 6 to $15 \mathrm{~mm}$, inferred from individual tagging, suggest $150 \mathrm{~m}$-rule-of-thumb for flower strip distances. J Hymenopt Res 77:105

Jäger EJ (ed) (2016) Rothmaler-Exkursionsflora von Deutschland. Gefäßpflanzen: Grundband. Springer, Heidelberg

Jennersten O (1988) Pollination in Dianthus deltoides (Caryophyllaceae): effects of habitat fragmentation on visitation and seed set. Conserv Biol 2:359-366

Johnson SD (2000) Batesian mimicry in the non-rewarding orchid Disa pulchra, and its consequences for pollinator behaviour. Biol J Linn Soc 71:119-132

Lack AJ (1982a) Competition for pollinators in the ecology of Centaurea scabiosa L. and Centaurea nigra L. III. Insect visits and the number of successful pollinations. New Phytol 91:321-339

Lack AJ (1982b) Competition for pollinators in the ecology of Centaurea scabiosa L. and Centaurea nigra L. II. Observations on nectar production. New Phytol 91:309-320

Landesamt für Natur, Umwelt und Verbraucherschutz Nordrhein-Westfalen (LANUV NRW), Floristische Kartierung NRW. www.florenkartierung-nrw.de; applied 04.05.2020

Marsden-Jones EM, Turrill WB (1954) British knapweeds. Ray Society, London

R Development Core Team (2017) R: a language and environment for statistical computing. R Foundation for Statistical Computing, Vienna

Schlindwein C, Wittmann D, Martins CF, Hamm A, Siqueira JA, Schiffler D, Machado IC (2005) Pollination of Campanula rapunculus $\mathrm{L}$. (Campanulaceae): how much pollen flows into pollination and into reproduction of oligolectic pollinators? Plant Syst Evol 250:147-156

von Hagen E, Aichhorn A (2003) Hummeln: bestimmen, ansiedeln, vermehren, schützen. Fauna-Verlag, Nottuln

Walther-Hellwig K, Frankl R (2000) Foraging habitats and foraging distances of bumblebees, Bombus spp. (Hym., Apidae), in an agricultural landscape. J Appl Entomol 124:299-306

Westrich P (2018) Die Wildbienen Deutschlands. Verlag Eugen Ulmer, Stuttgart

Zurbuchen A, Landert L, Klaiber J, Müller A, Hein S, Dorn S (2010) Maximum foraging ranges in solitary bees: only few individuals have the capability to cover long foraging distances. Biol Conserv 143:669-676

Publisher's Note Springer Nature remains neutral with regard to jurisdictional claims in published maps and institutional affiliations. 